\title{
Thyroid surgery during coronavirus-19 pandemic phases I, II and III: lessons learned in China, South Korea, Iran and Italy
}

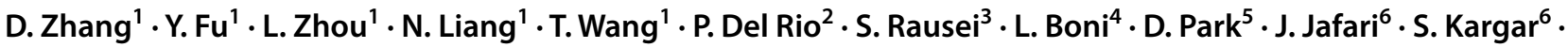 \\ H. Y. Kim ${ }^{5} \cdot$ M. L. Tanda ${ }^{7} \cdot$ G. Dionigi ${ }^{8} \cdot$ H. Sun ${ }^{1}$ (]
}

Received: 19 July 2020 / Accepted: 23 August 2020 / Published online: 2 September 2020

(c) Italian Society of Endocrinology (SIE) 2020

\begin{abstract}
Objective We compared demographic and clinic-pathological variables related to the number of surgeries for thyroid conditions or for cancer, morbidity, and fine needle aspiration (FNA) practices among Covid19 pandemic phases I, II, III and the same seasonal periods in 2019.

Methods The prospective database of the Division of Thyroid Surgery, China-Japan Union Hospital of Jilin University, Changchun, China was used for this study. Covid19 emergency levels were stratified according to the World Health Organization: phase I (January 25-February 25, 2020), phase II (February 26-March 19), phase III (March 20-April 20).

Results There were fewer outpatient FNAs and surgeries in 2020 than in 2019. There were no thyroid surgeries during phase I. There were also fewer surgeries for cancer with a significant reduction of advanced stage cancer treatments, mainly stage $\mathrm{T} 1 \mathrm{~b}$ N1a in phase II and T3bN1b in phase III. Operative times and postoperative stays were significantly shorter during the pandemic compared to our institutional baseline. In phase III, vocal cord paralysis (VCP) increased to $4.3 \%$ of our baseline numbers $(P=0.001)$. There were no cases of Covid19-related complications during the perioperative period. No patients required re-admission to the hospital.

Conclusion The Covid19 outbreak reduced thyroid surgery patient volumes. The decrease of Covid19 emergency plans contributed to unexpected outcomes (reduction of early stage cancer treatment, decreased operative times and hospital stays, increased VCP rate).
\end{abstract}

Keywords Thyroid · Surgery $\cdot$ Covid19 $\cdot$ SARS-CoV-2 $\cdot$ Thyroidectomy $\cdot$ Cancer $\cdot$ Morbidity $\cdot$ Surgical practice $\cdot$ Recurrent laryngeal nerve palsy $\cdot$ Italy $\cdot$ China $\cdot$ Iran $\cdot$ South Korea

\section{Introduction}

The historical moment that we are experiencing because of the severe acute respiratory syndrome coronavirus 2 (SARS$\mathrm{CoV}-2$ ) epidemic has forced a reformulation of the rules for the delivery of health services in surgical departments [1-3].

As the number of cases continued to rise, a rapidly increasing number of hospitals were designated by Governments for the exclusive admission of patients with SARS-CoV-2 (Covid19) to contain cross-infection [4-13].

Electronic supplementary material The online version of this article (https://doi.org/10.1007/s40618-020-01407-1) contains supplementary material, which is available to authorized users.

H. Sun

s_h@jlu.edu.cn

Extended author information available on the last page of the article
Politicians recommended the limitation of certain scheduled clinical activities [14-21] (Supplementary File 1).

The expected effect of the constraint on surgical planning due to the need to limit hospital access was to preserve only essential surgical procedures, freezing waiting times for surgeries for conditions without developmental risk and freeing professionals and patient care facilities for SARSCoV-2 patients $[5,7,10]$.

In these unprecedented circumstances, Chinese surgeons first, promptly, published strategic proposals for the treatment of neoplasms during the Covid19 epidemic $[6,7,9$, $10,13]$. Surgical societies developed practical recommendations for elective surgery calibrated on the basis of the scientific literature (Supplementary Files 2, 3) (Supplemenatry Table 1) [2, 3, 15, 22-29]. 
The impact of the SARS-CoV-2 endemic on thyroid surgery, is yet to be investigated [16]. The objectives of the current report were:

A. Compare thyroid surgery patient volumes, operations for cancer, morbidity, and trends for fine needle aspiration (FNA) practices, between the Covid19 outbreak and the same seasonal period during 2019.

B. Evaluate changes during the different phases of the Covid19 epidemic emergency levels [30-33].

C. Qualitatively compare opinions from thyroid surgery experts in those countries that were most severely affected in the first stage of the spread of the infectionChina, the Republic of Korea, the Islamic Republic of Iran and Italy [30]-(Supplementary Fig. 1).

\section{Materials and methods}

\section{Study design and data sources}

Retrospective analysis linked to the Institutional prospective web-based registry platform.

\section{Study approval and ethics statement}

No ethical license is required according to the Science Ethics Committee. Written informed consent was waived. The study complied with the Declaration of Helsinki.

\section{Study patients}

Case patients were recruited from the population of patients who were consecutively treated at the Division of Thyroid Surgery of the China-Japan Union Hospital of Jilin University (Changchun, China).

\section{Hospital category and setting}

The Division of Thyroid Surgery is a high-volume University-affiliated teaching hospital that provides health care to the entire Changchun. Changchun has a total population of $7,674,439$ [31].

\section{Time frame for analysis}

To reflect the effect of the Covid19 outbreak, patients who visited the hospital from January 25 to April 20, 2020 were included. Data from the same temporal period of the previous year (January 25-April 20, 2019) were collected for comparison.

\section{Definitions}

Covid19 This is a positive-sense single-stranded RNA virus, infecting humans $[4,30]$.

National and institutional policies Supplementary File 2 describes Chinese policies for thyroid surgery practice. Classification of pandemic Covid19 phases In China, the public health emergency was stratified into three pandemic phases:

- Phase I From January 25 to February 25, 2020 (time at which the Covid19 alert level was raised to the highest level).

- Phase II February 26 to March 19, 2020.

- Phase III March 20-April 20, 2020 [30-33] (Supplementary Fig. 2).

\section{Outpatient clinic, ultrasound examination and FNA}

Detail are offered in Supplementary File 2. FNA was offered according to the guidelines [34].

\section{Pre-operative screen test Covid19}

High resolution computerized tomography (CT) scan initially was proposed. The patient was required to be ambulatory $24-48$ h before hospitalization. Subsequently, a swab test for detection of Covid19 was substituted for the CT scan $[4,5]$. Surgery was postponed if the patient tested positive (Supplementary File 2).

\section{Laryngeal examination}

Pre-operative video laryngeal examination was scheduled after the SARS-CoV-2 screening test [35].

\section{Team model and procedures}

All procedures across phases were performed by a team comprised of the same surgeons. Intraoperative neural monitoring (IONM), antibiotic prophylaxis and early parathyroid hormone $(\mathrm{PTH})$ determinations (reference value is $15-65 \mathrm{pg} / \mathrm{ml}$ ) were offered preoperatively, and postoperatively across subsequent phases. 


\section{Multidisciplinary oncological meetings}

Telemedicine had a fundamental role in screening, followup and consultation during the SARS-CoV-2 periods of forced social distancing (Supplementary File 2).

\section{Study outcomes}

Data extracted from patients' notes included demographic, clinical, and pathologic variables. Surgical procedures were considered representative markers to evaluate patient volumes. The number of outpatient visits was collected as was the number of FNAs performed. Postoperative complications were recorded [21].

\section{Statistical analysis}

Continuous variables were expressed as mean (standard deviation), and categorical variables were expressed as percentage (frequency). Continuous variables were analyzed by $\mathrm{t}$ tests or analysis of variance, and categorical variables were analyzed by $\chi^{2}$ tests or $F$ exact tests. $P<0.05$ was considered statistically significant. Statistical analysis was performed using SPSS 22.0 SPSS, Chicago, USA, windows version).

\section{Results}

\section{Baseline characteristics of patients}

Table 1 compares baseline demographic and clinical-pathological characteristics of patients treated during Covid19 phases I, II, and III with our institutional baseline data from 2019. All patients had an ASA score I or II.

\section{Comparison of pandemic phase I vs. 2019}

There were 549 outpatients, a decrease of $93.3 \%$ compared to the same period in 2019. FNAs decreased by $99.7 \%$ $(P=0.000)$ (Fig. 1 and Supplementary Table 2$)$. There were no newly diagnosed thyroid malignancies and no surgeries.

\section{Phase II vs. 2019}

There was a $59 \%$ reduction in the number of outpatients $(n=3505$, Fig. 1), and a reduction of $62.9 \%$ in FNAs performed ( $n=195, P=0.271)$. One hundred patients $(51.3 \%)$ were diagnosed as malignant, a $3 \%$ decrease $(P=0.502)$. There were 117 inpatients $(56.3 \%$ reduction). The mean surgical time was reduced to $58.3 \pm 11.26 \min (P=0.000)$. The postoperative hospital stay declined to $2.8 \pm 0.9$
$(P=0.000)$ (Table 1). Mean tumor diameter was $3.92 \mathrm{~cm}$, a $14 \%$ decrease $(P=0.000)$. There were 107 malignant thyroidectomies ( $91.5 \%$ of the inpatients), a $2.5 \%$ decrease (mainly stage T1bN1a) (Table 2) $(P=0.015)$. There were 17 combined thyroiditis patients $(15.9 \%$ of inpatients), a $1.2 \%$ decrease $(P=0.878)$. There was one endoscopic thyroidectomy $(0.9 \%$ of inpatients, a $2.8 \%$ decrease, $(P=0.184) ; 51$ total thyroidectomies $(47.7 \%$ of inpatients, a $0.5 \%$ increase, $P=0.939) ; 106$ central lymph node dissections $(99.1 \%$ of inpatients, a $1.1 \%$ increase, $P=0.674)$; and 13 lateral lymph node dissections $(12.1 \%$ of inpatients, a $0.6 \%$ decrease, $P=0.886)$. Postoperative vocal cord paralysis decreased by $1.8 \%(P=0.568)$. In patients undergoing bilateral thyroidectomy $(n=51)$, postoperative PTH decreased by $41.2 \%$ compared to $49.9 \%$ in $2019(P=0.409)$. There was a $7 \%$ decrease in postoperative hypoparathyroidism $(n=8, P=0.408)$. There were no cases of Covid19 pneumonia or related complications in the perioperative period. No patients required intensive care treatment. No patients were re-admitted to the hospital.

\section{Phase III vs. 2019}

There was an $18.3 \%$ reduction in the number of outpatients treated ( $n=8467$, Fig. 1$)$, and a reduction in inpatients $(n=211)$. FNAs decreased by $30.1 \%(n=408$, $P=0.013)$. There were 225 newly diagnosed malignant patients (55.1\% of inpatients), a $2.3 \%$ decrease (Supplementary Table 2). Mean surgical time was reduced to $55.3 \pm 13.32 \mathrm{~min}(P=0.000)$. Postoperative hospitalization was reduced to $3.3 \pm 1.0$ days $(P=0.008)$. The mean tumor diameter was $3.92 \mathrm{~cm}$, a $16.1 \%$ decrease $(P=0.000)$. There were 186 thyroidectomies for cancer $(88.2 \%$ of inpatients, a $4.8 \%$ decrease) (Table 1). There were 27 combined thyroiditis patients $(14.5 \%$ of inpatients, a $2.3 \%$ decrease, $P=0.521)$; six endoscopic thyroidectomies (2.8\% of inpatients, a $0.8 \%$ increase, $P=0.564) ; 83$ total thyroidectomies (44.6\% of inpatients, a $4.5 \%$ decrease, $P=0.394)$. 182 central lymph node dissections $(97.8 \%$ of inpatients, a $1.4 \%$ decrease, $P=0.223)$; and 20 lateral lymph node dissections ( $10.8 \%$ of inpatients, a $0.7 \%$ decrease, $P=0.064$ ). There was a significant reduction of $\mathrm{T} 3 \mathrm{bN} 1 \mathrm{~b}$ PTC treated (Table 2). Thirteen inpatients (4.3\%) had vocal cord paralysis, a $4.1 \%$ increase $(P=0.000)$. In patients undergoing bilateral thyroidectomy $(n=83)$, postoperative PTH decreased by $40.3 \%$ compared with $7.9 \%$ during the same period in 2019. Postoperative hypoparathyroidism was found in 11 inpatients $(13.4 \%)$, a $1.9 \%$ decrease. There were no cases of Covid19-related complications in the perioperative period. No patients required intensive care treatment, and none were re-admitted to the hospital. 
Table 1 Baseline demographic and clinics-pathological characteristics of patients treated during Covid19 phase I, II, III and 2019 same period time

\begin{tabular}{|c|c|c|c|c|c|c|c|c|c|}
\hline & \multicolumn{3}{|c|}{$1.25-2.25$} & \multicolumn{3}{|l|}{$2.26-3.20$} & \multicolumn{3}{|l|}{$3.21-4.20$} \\
\hline & 2020 & 2019 & $\mathrm{P} 1$ & 2020 & 2019 & $\mathrm{P} 2$ & 2020 & 2019 & P3 \\
\hline Number & 0 & 163 & - & 117 & 268 & - & 211 & 300 & - \\
\hline Age (years) & - & $42.5 \pm 10.8$ & - & $42.6 \pm 10.9$ & $43.0 \pm 9.6$ & 0.719 & $43.2 \pm 12.5$ & $42.0 \pm 10.7$ & 0.245 \\
\hline Gender (M/F) & - & $36 / 127$ & - & $24 / 93$ & $50 / 218$ & 0.675 & $33 / 178$ & $62 / 238$ & 0.167 \\
\hline \multicolumn{10}{|l|}{ ASA grade } \\
\hline I & - & $135(82.8)$ & - & $106(90.6)$ & $227(84.7)$ & 0.079 & $183(86.7)$ & $246(82.0)$ & 0.094 \\
\hline II & - & $28(17.2)$ & & $11(9.4)$ & $41(15.3)$ & & $28(13.3)$ & $54(18.0)$ & \\
\hline Mean operating time (min) & - & $53.8 \pm 10.23$ & - & $58.3 \pm 11.26$ & $63.2 \pm 13.21$ & $0.000 * *$ & $55.3 \pm 13.32$ & $60.9 \pm 15.11$ & $0.000 * *$ \\
\hline $\begin{array}{l}\text { Postoperative hospital stay time } \\
\text { (D) }\end{array}$ & - & $3.5 \pm 1.1$ & - & $2.8 \pm 0.9$ & $3.2 \pm 1.0$ & $0.000 * *$ & $3.3 \pm 1.0$ & $3.7 \pm 2.0$ & $0.008 * *$ \\
\hline $\begin{array}{l}\text { Endoscopic/robot thyroidectomy } \\
(n, \%)\end{array}$ & - & $9(5.5)$ & - & $1(0.9)$ & $10(3.7)$ & 0.184 & $6(2.8)$ & $6(2.0)$ & 0.564 \\
\hline Open thyroidectomy $(n, \%)$ & - & $154(94.5)$ & & $116(99.1)$ & $258(96.3)$ & & $205(97.2)$ & $294(98.0)$ & \\
\hline Benign $(n, \%)$ & - & $9(5.5)$ & - & $10(8.5)$ & $16(6.0)$ & 0.380 & $25(11.8)$ & $21(7.0)$ & 0.083 \\
\hline Unilateral & - & 7 & - & $7(70.0)$ & $12(75.0)$ & 0.780 & $18(72.0)$ & $17(81.0)$ & 0.514 \\
\hline Bilateral & - & 2 & - & $3(30.0)$ & $4(25.0)$ & & $7(28.0)$ & $4(19.0)$ & \\
\hline Maximum nodule diameter $(\mathrm{cm})$ & - & $4.73 \pm 1.81$ & - & $3.92 \pm 1.39$ & $4.60 \pm 1.50$ & $0.000^{* *}$ & $3.92 \pm 1.42$ & $4.67 \pm 1.94$ & $0.000 * *$ \\
\hline Malignant $(n, \%)$ & - & $154(94.5)$ & - & $107(91.5)$ & $252(94.0)$ & 0.380 & $186(88.2)$ & $279(93.0)$ & 0.083 \\
\hline Unilateral & - & 72 & - & $56(52.3)$ & $133(52.8)$ & 0.939 & $103(55.4)$ & $142(50.9)$ & 0.394 \\
\hline Bilateral & - & 82 & - & $51(47.7)$ & $119(47.2)$ & & $83(44.6)$ & $137(49.1)$ & \\
\hline PTH (preoperative) (pg/ml) & - & $51.99 \pm 23.5$ & - & $44.44 \pm 19.47$ & $48.75 \pm 17.13$ & $0.030^{*}$ & $51.47 \pm 16.4$ & $52.71 \pm 21.3$ & 0.478 \\
\hline $\begin{array}{l}\text { PTH (30 min after operation) } \\
\quad(\mathrm{pg} / \mathrm{ml})\end{array}$ & - & $23.98 \pm 18.33$ & - & $26.11 \pm 22.38$ & $24.42 \pm 21.77$ & 0.488 & $30.75 \pm 25.53$ & $27.33 \pm 22.11$ & 0.107 \\
\hline Reduce the ratio (\%) & - & 53.9 & & 41.2 & 49.9 & 0.409 & 40.2 & 48.1 & 0.559 \\
\hline Hypoparathyroidism $(n, \%)$ & - & $19(23.2)$ & - & $8(15.7)$ & $27(22.7)$ & 0.408 & $11(13.4)$ & $21(15.3)$ & 0.844 \\
\hline Transient/persistent & - & $15 / 4$ & - & - & $25 / 2$ & - & - & $18 / 3$ & - \\
\hline Combined thyroiditis $(n, \%)$ & - & $38(24.7)$ & - & $17(15.9)$ & $43(17.1)$ & 0.878 & $27(14.5)$ & $47(16.8)$ & 0.521 \\
\hline $\begin{array}{l}\text { Central lymph node dissection } \\
(n, \%)\end{array}$ & - & $154(100)$ & - & $106(99.1)$ & $247(98.0)$ & 0.674 & $182(97.8)$ & $277(99.2)$ & 0.223 \\
\hline $\begin{array}{l}\text { Lateral lymph node dissection } \\
\quad(n, \%)\end{array}$ & - & $23(14.9)$ & - & $13(12.1)$ & $32(12.7)$ & 0.886 & $20(10.8)$ & $32(11.5)$ & 0.064 \\
\hline $\begin{array}{l}\text { Postoperative vocal cord paralysis } \\
(n, \%)\end{array}$ & - & $12(4.9)$ & - & $3(1.8 \%)$ & $11(2.8)$ & 0.568 & $13(4.3)$ & $1(0.2)$ & $0.000 * *$ \\
\hline Transient/persistent & - & $12 / 0$ & - & - & $11 / 0$ & - & - & $1 / 0$ & - \\
\hline
\end{tabular}

$* P<0.05, * * P<0.01$

\section{Discussion}

This is the first report to review the impact of Covid19 on thyroid surgery specialists' practice stratified into the three pandemic phases. In the case of subsequent waves of SARSCoV-2 pandemic, we may use our results as a clinical guide.

In phase I, we recorded a $93.3 \%$ decrease in outpatients, a $99.7 \%$ reduction in FNAs, no newly diagnosed thyroid malignancies and no surgeries. Recent research applying a statistical model to a series of real data collected worldwide estimated that in March 2020 more than 28 million surgeries may have been canceled due to the Covid19 pandemic [29]. The research was based on a series of interviews with surgical experts in 190 countries who were asked what interventions would be postponed during the peak of the pandemic [29]. It appeared that on average, $72 \%$ of non-essential interventions would be canceled, corresponding to a total of $28,404,603$ operations globally. Of the total, $90 \%$ of the canceled operations would be linked to a benign pathology, $8.2 \%$ would be represented by surgery for a tumor and $1.6 \%$ by obstetric operations such as an elective cesarean section. The major limitation of the study is that it is presumptive, i.e. based on estimates by respondents in countries where the pandemic had just arrived or had not yet reached its peak [29]. 


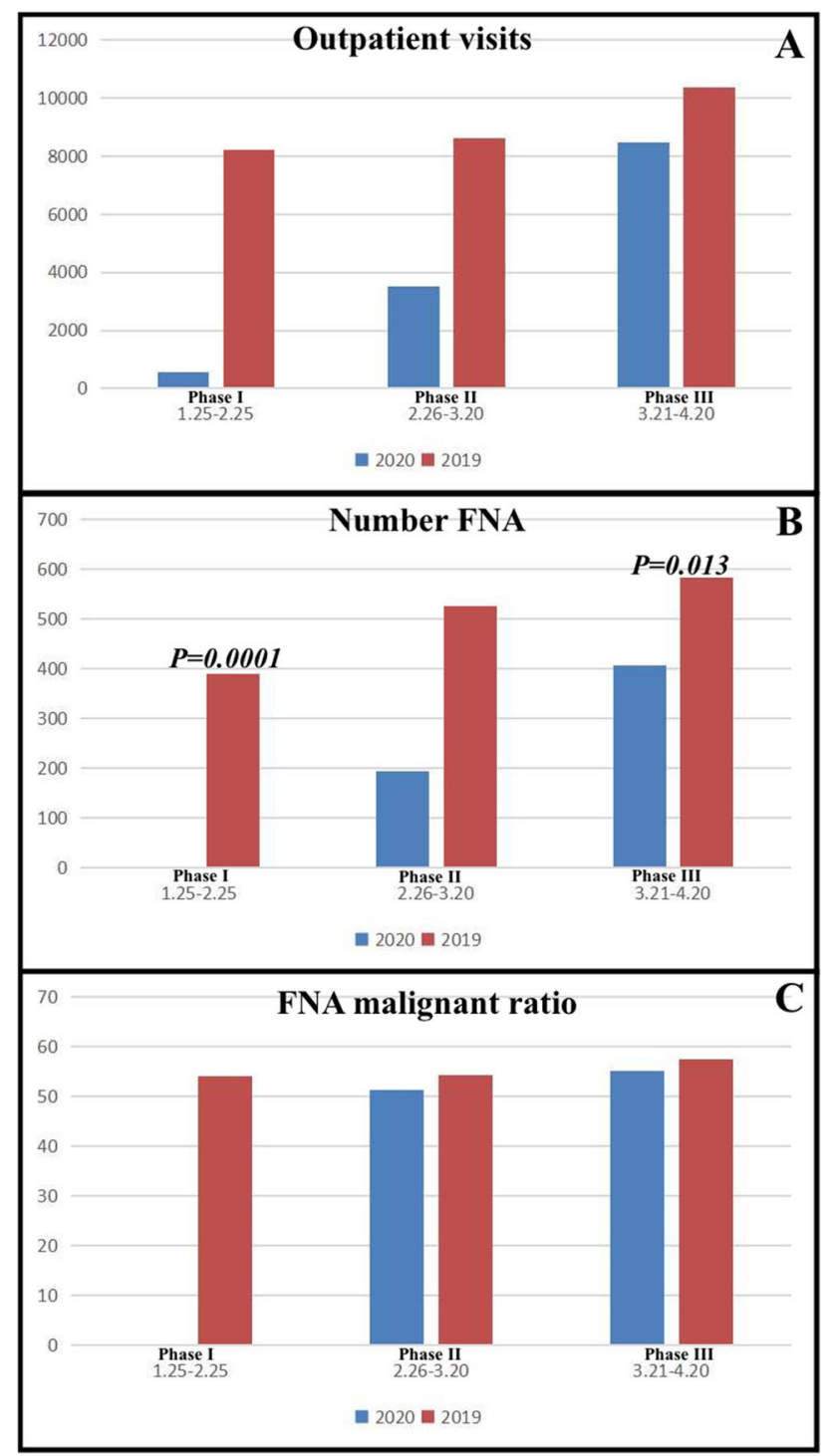

Fig. 1 Graphs showing comparison of a the number of outpatients visits, b number of FNA and c FNA proportion of malignancy, at the Division of Thyroid Surgery of the China-Japan Union Hospital of Jilin University (Changchun, People's Republic of China), during Covid19 emergency phases I, II, III and year 2019

\section{Operative volume}

Our results are in accordance with national policies and endocrine surgical society guidelines recommending postponement of non-emergent surgery (Supplementary Table 1, Supplementary File 2). As surgical specialists, thyroid surgeons perform routinely a high volume of scheduled surgeries. Comparing the overall trend of thyroid surgical procedures (scheduled, hospitalization, inpatient), there was a decline between 2019 and 2020 (Fig. 1). This change was reassessed following the completion of pandemic phase III. There also was a significant decrease in operative and postoperative time.

\section{Thyroid cancer}

The prevalence of interventions performed for cancer was similar to that for all surgical activity: the reduction includes the number of thyroidectomies for cancer, outpatient clinic visit, and the number and proportion of FNAs for malignancy. Interestingly, compared to 2019, there was a significant reduction of stage T1b N1a in phase II and T3bN1b in phase III (Table 2). The effect of the Covid19 lockdown on outcomes for untreated or under-diagnosed thyroid cancer patients is still unknown. De facto, most thyroid cancers have excellent prognosis [34].

\section{ASA score and surgical complexity}

The proportion of ASA score I patients in 2020 was significantly higher compared with the same period in 2019, probably due to Anesthesiologist selection bias. There were no significant differences in complexity of surgery with similar patient volumes for endoscopies, lobectomies, and lymph node dissections.

\section{Ensuring safe surgery}

Surgeries were performed maintaining the safety of healthcare personnel and patients. There were no cases of Covid19-related complications in the perioperative period, and no patients required intensive care treatment or readmission to the hospital. Intraoperative neural monitoring (IONM) was offered. In phase II, postoperative VCP decreased by $1.8 \%$. In phase III, VCP increased significantly to $4.3 \%$ of baseline $(P=0.001)$. The data are in some ways unexpected. They may reflect the selection criteria for cancer surgery (Table 2). Furthermore, during the SARS-CoV-2 outbreak, the treated patients were more likely to experience a decrease in serum PTH. In phase II patients undergoing bilateral thyroidectomy, postoperative PTH decreased by $41.2 \%$, vs. $8.7 \%$ in 2019 . In phase III patients undergoing bilateral thyroidectomy, postoperative PTH decreased by 40.3\% compared with $7.9 \%$ in 2019 .

An international multicenter study conducted in 235 hospitals in 24 countries included all patients undergoing surgery with confirmed SARS-CoV-2 infections within seven days before or 30 days after surgery [27]. In total there were 1128 patients who underwent surgery between 1 January and 31 March 2020, of which 835 (74.0\%) underwent an emergency intervention and 280 (24.8\%) had an elective surgery. SARS-CoV-2 infection was confirmed before surgery in 294 patients $(26.1 \%)$. The 30 -day mortality rate was $23.8 \%$ (268 out of 1128 ). 
Table 2 Postoperative pathology of patients during Covid19 phase I, II, III and 2019 same period time

\begin{tabular}{|c|c|c|c|c|c|c|c|c|c|}
\hline & \multicolumn{3}{|c|}{$1.25-2.25$} & \multicolumn{3}{|l|}{$2.26-3.20$} & \multicolumn{3}{|l|}{$3.21-4.20$} \\
\hline & 2020 & $\begin{array}{l}2019 \\
n(\%)\end{array}$ & P1 & $\begin{array}{l}2020 \\
n(\%)\end{array}$ & $\begin{array}{l}2019 \\
n(\%)\end{array}$ & $\mathrm{P} 2$ & $\begin{array}{l}2020 \\
n(\%)\end{array}$ & $\begin{array}{l}2019 \\
n(\%)\end{array}$ & P3 \\
\hline Number & 0 & 163 & - & 117 & 268 & - & 211 & 300 & - \\
\hline Benign & - & $9(5.5)$ & - & $10(8.5)$ & $16(6.0)$ & 0.380 & $25(11.8)$ & $21(7.0)$ & 0.083 \\
\hline Malignant & - & $154(94.5)$ & & 107 (91.5) & $252(94.0)$ & & $186(88.2)$ & $279(93.0)$ & \\
\hline T1a & - & $80(49.1)$ & - & $72(61.5)$ & $145(54.1)$ & 0.182 & $114(54.0)$ & $150(50.0)$ & 0.429 \\
\hline No & - & $50(30.7)$ & - & $43(36.8)$ & $91(34.0)$ & 0.642 & $82(38.9)$ & $91(30.3)$ & 0.047 \\
\hline N1a & - & $28(17.2)$ & - & $28(23.9)$ & $47(17.5)$ & 0.162 & $26(12.3)$ & $50(16.7)$ & 0.207 \\
\hline N1b & - & $2(1.2)$ & - & $1(0.9)$ & 7 (2.6) & 0.444 & $6(2.8)$ & $9(3.0)$ & 0.395 \\
\hline $\mathrm{T} 1 \mathrm{~b}$ & - & $25(15.3)$ & - & $5(4.3)$ & $34(12.7)$ & $0.010 *$ & $30(14.2)$ & $45(15.0)$ & 0.899 \\
\hline N0 & - & $5(3.1)$ & - & $1(0.9)$ & $11(4.1)$ & 0.116 & $10(4.7)$ & $17(5.7)$ & 0.918 \\
\hline N1a & - & $11(6.7)$ & - & $1(0.9)$ & $17(6.3)$ & $0.017 *$ & $11(5.2)$ & $20(6.7)$ & 0.575 \\
\hline $\mathrm{N} 1 \mathrm{~b}$ & - & $9(5.5)$ & - & $3(2.6)$ & $6(2.2)$ & 0.846 & $9(4.3)$ & $8(2.7)$ & 0.329 \\
\hline $\mathrm{T} 2$ & - & $2(1.2)$ & - & $3(2.6)$ & $8(3.0)$ & 0.820 & $10(4.7)$ & $8(2.7)$ & 0.230 \\
\hline N0 & - & $0(0)$ & - & $0(0)$ & $2(0.7)$ & - & $4(1.9)$ & $4(1.3)$ & 0.723 \\
\hline $\mathrm{N} 1 \mathrm{a}$ & - & $2(1.2)$ & - & $2(1.7)$ & $5(1.9)$ & 0.916 & $3(1.4)$ & $1(0.3)$ & 0.311 \\
\hline N1b & - & $0(0)$ & - & $1(0.9)$ & $1(0.4)$ & 0.516 & $3(1.4)$ & $3(1.0)$ & 0.695 \\
\hline T3a & - & $1(0.6)$ & - & $2(1.7)$ & $0(0)$ & - & $0(0)$ & $3(1.0)$ & - \\
\hline N0 & - & $1(0.6)$ & - & $1(0.9)$ & 0 & - & 0 & $1(0.3)$ & - \\
\hline $\mathrm{N} 1 \mathrm{a}$ & - & $0(0)$ & - & $0(0)$ & 0 & - & 0 & $2(0.7)$ & - \\
\hline $\mathrm{N} 1 \mathrm{~b}$ & - & $0(0)$ & - & $1(0.9)$ & 0 & - & 0 & 0 & - \\
\hline $\mathrm{T} 3 \mathrm{~b}$ & - & 45 (27.6) & - & $24(20.5)$ & $63(23.5)$ & 0.597 & $32(15.2)$ & 68 (22.7) & $0.041^{*}$ \\
\hline NO & - & $19(11.7)$ & - & $14(12.0)$ & $23(8.6)$ & 0.347 & $20(9.5)$ & $42(14.0)$ & 0.132 \\
\hline N1a & - & $16(9.8)$ & - & $7(6.0)$ & $25(9.3)$ & 0.321 & $11(5.2)$ & $18(6.0)$ & 0.847 \\
\hline N1b & - & $10(6.1)$ & - & $3(2.6)$ & 15 (5.6) & 0.294 & $1(0.5)$ & $8(2.7)$ & 0.088 \\
\hline $\mathrm{T} 4 \mathrm{a}$ & - & $1(0.6)$ & - & $1(0.9)$ & $3(1.1)$ & 0.814 & $0(0)$ & $4(1.3)$ & - \\
\hline N0 & - & $0(0)$ & - & $0(0)$ & $0(0)$ & - & 0 & $1(0.3)$ & - \\
\hline N1a & - & $1(0.6)$ & - & $0(0)$ & $1(0.4)$ & - & 0 & $2(0.7)$ & - \\
\hline N1b & - & $0(0)$ & - & $1(0.9)$ & $2(0.7)$ & 0.911 & 0 & $1(0.3)$ & - \\
\hline
\end{tabular}

Lung complications occurred in $51.2 \%$ of patients. The authors conclude that postoperative pulmonary complications occur in half of patients with a perioperative SARSCoV-2 infection and are associated with high mortality [27].

\section{Republic of Korea, Islamic Republic of Iran and Italy}

Associated information from geographical regions that have been severely affected by the SARS-CoV-2 pandemic is available in Supplementary File 5. This Supplementary reports international experience with thyroid surgery during various points of the pandemic. While the time points (phases) are benchmarked using WHO dates and emergency level, there is inevitable variation in Covid19 impact depending on local surge factors. Care patterns, allowances for or restrictions on elective surgery are all based on local (hospital-level/surgeon-level) decision making.

\section{Limitations of the study}

As thyroid surgery specialists, we are often not confronted with patients diagnosed with Covid19.

Currently, there is no clear evidence that the SARSCoV-2 has direct impact on any form of thyroid disease [16].

The present work is based on the currently available evidence concerning surgical and oncological management in the course of the SARS-CoV-2 epidemic. Recommendations may be subject to subsequent updates in case of new and relevant scientific findings(Supplementary Files 1, 2, 3, 4) (Supplemenatry Table 1).

We have presented data from academic hospitals dedicated to thyroid surgery. Data from hospitals with low volumes of thyroid surgery are missing from this report.

The data need to be further investigated. However, it does not seem that the reduced number of thyroid surgeries depends only on a decreased accessibility to hospitals because at the same time there has been an increased number of patients refusing hospitalization for the surgery. 
At present, we cannot provide definitive numbers about endocrinology clinics or radioiodine treatment volumes. Furthermore, in view of the limited resources, alternative treatments should be considered. The present report didn't determine whether the number of alterative treatments (for example, alcohol or radio-frequency thyroid nodule ablations) were reduced.

The type of delivery setting for thyroid surgery was not analyzed. The hypothesis is that the reduction of thyroid surgery volume is less marked for day surgery and for outpatient surgery compared to ordinary hospitalization.

Some patients included in this report (phase III) had a short follow-up interval and hence late presentation of complications may not be accurately reported.

The impact on the thyroid surgery trainee was not specifically evaluated in the present report.

Finally, details about hospital budgets have not been calculated.

Acknowledgements The Authors appreciate the contributions of the following investigators: Members of the Chinese College of Surgeons-Thyroid Surgeons Committee, Chinese Research Hospital Association-Thyroid Disease Professional Committee, China Association of Medical Equipment-Thyroid Surgery Equipment Committee. Members of the Società Italiana Unita di Endocrinochirurgia (SIUEC), Società Italiana di Chirurgia Oncologica (SICO), European Society Endocrine Surgery (ESES); Members of the International Neural Monitoring Study Group (INMSG); Antonio Macrì, Antonella Pino, Ettore Caruso (University of Messina, Italy).

Author contributions HS, DZ, GD: conceptualization, writing, final review and final approval; HS, DZ, GD: data analysis, drafting the article and final approval; all authors: conceptualization, data collection, critical revision for important intellectual content and final approval. This publication has been approved by all co-authors.

Funding This work was supported by the China Postdoctoral Science Foundation (no. 2017M611313), Department of Science and Technology of Jilin Province (no. 20190201225JC) and Department of Finance of Jilin Province (no. SCZSY201714), China.

Data availability All data and material are available on reasonable request. The work described has not been published before; it is not under consideration for publication anywhere else.

\section{Compliance with ethical standards}

Conflict of interest All Authors report having no relationships that could be construed as a conflict of interest.

Ethical approval All procedures performed in studies involving human participants were in accordance with the ethical standards of the institutional and national research committee and in accordance with the Declaration of Helsinki of 1964 and its later amendments or comparable ethical standards.

Informed consent Informed consent was obtained from all individual participants involved in the study.

\section{References}

1. Aminian A, Safari S, Razeghian-Jahromi A, Ghorbani M, Delaney CP (2020) COVID-19 outbreak and surgical practice: unexpected fatality in perioperative period. Ann Surg. https://doi. org/10.1097/SLA.0000000000003925([Epub ahead of print] PubMed PMID: 32221117)

2. Indini A, Aschele C, Cavanna L, Clerico M, Daniele B, Fiorentini G (2020) Reorganisation of medical oncology departments during the novel coronavirus disease-19 pandemic: a nationwide Italian survey. Eur J Cancer 132:17-23

3. Society of American Gastrointestinal and Endoscopic Surgeons (SAGES) (2020) SAGES AND EAES recommendations regarding surgical response to COVID-19 crisis [Internet]. Los Angeles (CA): Society of American Gastrointestinal and Endoscopic Surgeons. https://www.sages.org/recommendations-surgi cal-response-covid-19/. Cited 30 Apr 2020

4. Li Q, Guan X, Wu P, Wang X, Zhou L, Tong Y, Ren R, Leung KSM, Lau EHY, Wong JY, Xing X, Xiang N, Wu Y, Li C, Chen Q, Li D, Liu T, Zhao J, Liu M, Tu W, Chen C, Jin L, Yang R, Wang Q, Zhou S, Wang R, Liu H, Luo Y, Liu Y, Shao G, Li H, Tao Z, Yang Y, Deng Z, Liu B, Ma Z, Zhang Y, Shi G, Lam TTY, Wu JT, Gao GF, Cowling BJ, Yang B, Leung GM, Feng Z (2020) Early transmission dynamics in Wuhan, China, of novel coronavirus-infected pneumonia. N Engl J Med 382(13):1199_ 1207. https://doi.org/10.1056/NEJMoa2001316(Epub 2020 Jan 29 PubMed PMID: 31995857)

5. Zhu N, Zhang D, Wang W, Li X, Yang B, Song J, Zhao X, Huang B, Shi W, Lu R, Niu P, Zhan F, Ma X, Wang D, Xu W, Wu G, Gao GF, Tan W, China Novel Coronavirus Investigating, and Research Team (2020) A novel coronavirus from patients with pneumonia in China, 2019. N Engl J Med. 382(8):727-733. https://doi.org/10.1056/NEJMoa2001017(Epub 2020 Jan 24. PubMed PMID: 31978945)

6. Chen YH, Peng JS (2020) Treatment strategy for gastrointestinal tumor under the outbreak of novel coronavirus pneumonia in China. Zhonghua Wei Chang Wai Ke Za Zhi 23(2):I-IV. https ://doi.org/10.3760/cma.j.issn.1671-0274.2020.02.001(Chinese. PubMed PMID: 32074786)

7. Chan JYK, Wong EWY, Lam W (2020) Practical aspects of otolaryngologic clinical services during the 2019 novel coronavirus epidemic: an experience in Hong Kong. JAMA Otolaryngol Head Neck Surg. https://doi.org/10.1001/jamao to.2020.0488([Epub ahead of print] PubMed PMID: 32196070)

8. Zhu W, Wang Y, Xiao K, Zhang H, Tian Y, Clifford SP, Xu J, Huang $\mathbf{J}$ (2020) Establishing and managing a temporary coronavirus disease 2019 specialty hospital in Wuhan, China. Anesthesiology. https://doi.org/10.1097/ALN.000000000000329 9([Epub ahead of print] PubMed PMID: 32195700)

9. Tao KX, Zhang BX, Zhang P, Zhu P, Wang GB, Chen XP, General Surgery Branch of Hubei Medical Association, General Surgery Branch of Wuhan Medical Association (2019) Recommendations for general surgery clinical practice in, coronavirus disease situation. Zhonghua Wai Ke Za Zhi 58(3):170-177. https ://doi.org/10.3760/cma.j.issn.0529-5815.2020.03.003(Chinese. PubMed PMID: 32187920)

10. Li Y, Qin JJ, Wang Z, Yu Y, Wen YY, Chen XK, Liu WX, Li Y (2020) Surgical treatment for esophageal cancer during the outbreak of COVID-19. Zhonghua Zhong Liu Za Zhi 42:E003. https://doi.org/10.3760/cma.j.cn112152-20200226-00128

11. Ti LK, Ang LS, Foong TW, Ng BSW (2020 Mar 6) What we do when a COVID-19 patient needs an operation: operating room preparation and guidance. Can J Anaesth. https://doi. org/10.1007/s12630-020-01617-4 
12. General Office of the National Health and Health Commission (2020) Notice of the General Office of the National Health and Health Commission on Strengthening Medical Service Management during Epidemic Situations to Meet People's Basic Medical Needs [EB/OL]. https://www.nhc.gov.cn/yzygj/s7659/20200 2/6d5a8556c5ce46368263711698d8237a.shtml. Accessed $21 \mathrm{Feb}$ 2020

13. Liang W, Guan W, Chen R, Wang W, Li J, Xu K (2020) Cancer patients in SARS-CoV-2 infection: a nationwide analysis in China. Lancet Oncol 21(3):335-337

14. https://www.trovanorme.salute.gov.it/norme/dettaglioA tto?id=73717. Accessed 1 June 2020

15. Patriti A, Baiocchi GL, Catena F, Marini P, Catarci M, FACS on behalf of the Associazione Chirurghi Ospedalieri Italiani (ACOI) (2020) Emergency general surgery in Italy during the COVID19 outbreak: first survey from the real life. World J Emerg Surg 15(1):36ww

16. Bartalena L, Chiovato L, Marcocci C, Vitti P, Piantanida E, Tanda ML (2020) Management of Graves' hyperthyroidism and orbitopathy in time of COVID-19 pandemic. J Endocrinol Investig. https://doi.org/10.1007/s40618-020-01293-7

17. Mascagni D, Eberspacher C, Mascagni P et al (2020) From high volume to "zero" proctology: Italian experience in the COVID era. Int J Colorectal Dis. https://doi.org/10.1007/s00384-020-03622-X

18. Zheng MH, Boni L, Fingerhut A (2020 Mar 26) Minimally invasive surgery and the novel coronavirus outbreak: lessons learned in China and Italy. Ann Surg. https://doi.org/10.1097/SLA.00000 00000003924

19. Repubblica Italiana-Ministero della Salute. Piano nazionale di governo delle liste di attesa per il triennio 2019-2021. https:// www.salute.gov.it/imgs/C_17_pubblicazioni_2824_allegato.pdf. Accessed 1 June 2020

20. Novel Coronavirus Pneumonia Emergency Response Epidemiology Team (2020) The epidemiological characteristics of an outbreak of 2019 novel coronavirus diseases (COVID-19) in China. Zhonghua Liu Xing Bing Xue Za Zhi 41(2):145-151

21. Lei S, Jiang F, Su W et al (2020) Clinical characteristics and outcomes of patients undergoing surgeries during the incubation period of COVID-19 infection. EClinicalMedicine. https://doi. org/10.1016/j.eclinm.2020.100331

22. https://www.sicoweb.it/raccomandazioni-sico.pdf. Accessed 1 June 2020

23. https://www.endocrinesurgery.org/assets/COVID-19/Prioritize -Backlog-of-Cases.pdf. Accessed 1 June 2020

24. https://www.baets.org.uk/wp-content/uploads/2020/05/BAETS -Statement-Thyroid-Cancer-Covid-0520.pdf. Accessed 1 June 2020

25. Torretta S, Gaini LM, Pignataro L (2020) Why Italian ENT physicians should be aware of SARS-CoV-2. Acta Otorhinolaryngol Ital. https://doi.org/10.14639/0392-100X-N0738([Epub ahead of print] PubMed PMID: 32225995)

26. Vukkadala N, Qian ZJ, Holsinger FC, Patel ZM, Rosenthal E (2020) COVID-19 and the otolaryngologist-preliminary evidence-based review. Laryngoscope. https://doi.org/10.1002/ lary.28672([Epub ahead of print] PubMed PMID: 32219846)

27. COVIDSurg Collaborative (2020) Mortality and pulmonary complications in patients undergoing surgery with perioperative SARS-CoV-2 infection: an international cohort study. Lancet. https://doi.org/10.1016/S0140-6736(20)31182-X

28. COVIDSurg Collaborative (2020) Global guidance for surgical care during the COVID-19 pandemic. Br J Surg. https://doi. org/10.1002/bjs.11646

29. Nepogodiev D, Bhangu A, CovidSurg Collaborative (2020) Elective surgery cancellations due to the COVID-19 pandemic: global predictive modelling to inform surgical recovery plans. Br J Surg. https://doi.org/10.1002/bjs.11746
30. Coronavirus COVID-19 Global Cases by the Center for Systems Science and Engineering (CSSE) at Johns Hopkins University (2020) https://gisanddata.maps.arcgis.com/apps/opsdashboard/ index.html\#/bda7594740fd40299423467b48e9ecf6. Accessed 1 June 2020

31. Statistics Communique on National Economy and Social Development of Changchun, 2010 (in Chinese). 5 June 2011. Archived from the original on 28 July 2011. Retrieved 17 February 2012

32. "Statement on the second meeting of the International Health Regulations (2005) Emergency Committee regarding the outbreak of novel coronavirus (2019-nCoV)". World Health Organization (WHO). 30 January 2020. Archived from the original on 31 January 2020. Retrieved 30 January 2020

33. "WHO Director-General's opening remarks at the media briefing on COVID-19-11 March 2020". World Health Organization. 11 March 2020. Retrieved 11 March 2020

34. Haugen BR, Alexander EK, Bible KC et al (2016) 2015 American thyroid association management guidelines for adult patients with thyroid nodules and differentiated thyroid cancer: the American Thyroid Association guidelines task force on thyroid nodules and differentiated thyroid cancer. Thyroid 26(1):1-133. https://doi. org/10.1089/thy.2015.0020

35. Dionigi G, Boni L, Rovera F, Rausei S, Castelnuovo P, Dionigi R (2010) Postoperative laryngoscopy in thyroid surgery: proper timing to detect recurrent laryngeal nerve injury. Langenbecks Arch Surg 395(4):327-331. https://doi.org/10.1007/s00423-009-0581-x

36. The Korean Ministry of Health and Welfare (2020) Coronavirus disease (COVID-19) infection. https://ncov.mohw.go.kr/baroV iew2.do?brdId=4\&brdGubun=42. Accessed 10 June 2020

37. Choi JY (2020) Covid-19 in South Korea. Postgrad Med J 0:1-4

38. Korean Society of Infectious Diseases, Korean Society of Pediatric Infectious Disease, Korean Society of Epidemiology, Korean Society for Antimicrobial Therapy, Korean Society for Healthcare-associated Infection Control and Prevention, Korea Centers for Disease Control and Prevention. Report on the Epidemiological Features of Coronavirus Disease 2019 (COVID-19) (2020) Outbreak in the Republic of Korea from January 19 to March 2, 2020. J Korean Med Sci 35(10):e112

39. Askari A, Arasteh P, Jabalameli M, Bagherifard A, Razi M (2020) COVID-19 and orthopaedic surgery: experiences from Iran. J Bone Jt Surg Am. https://doi.org/10.2106/JBJS.20.00631

40. https://www.salute.gov.it/portale/listeAttesa/dettaglioConten utiListeAttesa.jsp?lingua $=$ italiano $\& i d=5140 \&$ area $=$ listeAttes $\mathrm{a} \& \mathrm{menu}=$ vuoto. Accessed 1 June 2020

41. https://www.siaarti.it/News/COVID19\%2520-\%2520docume nti\%2520SIAARTI.aspx. Accessed 1 June 2020

42. Dionigi G, Bacuzzi A, Boni L, Rausei S, Rovera F, Dionigi R (2012) Visualization versus neuromonitoring of recurrent laryngeal nerves during thyroidectomy: what about the costs? World J Surg 36(4):748-754. https://doi.org/10.1007/s00268-012-1452-0

43. Mintz Y, Arezzo A, Boni L et al (2020) The risk of COVID-19 transmission by laparoscopic smoke may be lower than for laparotomy: a narrative review. Surg Endosc. https://doi.org/10.1007/ s00464-020-07652-y

44. Schneider R, Randolph GW, Dionigi G et al (2018) International neural monitoring study group guideline 2018 part I: staging bilateral thyroid surgery with monitoring loss of signal. Laryngoscope 128(Suppl 3):S1-S17. https://doi.org/10.1002/lary.27359

Publisher's Note Springer Nature remains neutral with regard to jurisdictional claims in published maps and institutional affiliations. 


\section{Affiliations}

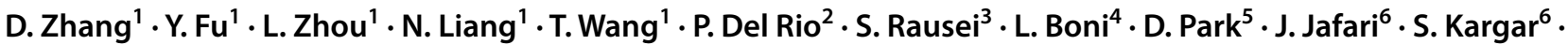 H. Y. Kim ${ }^{5} \cdot$ M. L. Tanda ${ }^{7} \cdot$ G. Dionigi ${ }^{8} \cdot$ H. Sun ${ }^{1}$}

P. Del Rio

paolo.delrio@unipr.it

S. Rausei

stefano.rausei@gmail.com

L. Boni

luigi.boni@unimi.it

D. Park

dawon.park@gmail.com

J. Jafari

jamalnedooshan@yahoo.com

S. Kargar

saeedkargar@yahoo.com

H. Y. Kim

hoonyubkim@korea.ac.kr

G. Dionigi

gdionigi@unime.it

1 Division of Thyroid Surgery, China-Japan Union Hospital of Jilin University, Jilin Provincial Key Laboratory of Surgical Translational Medicine, Jilin Provincial Precision Medicine Laboratory of Molecular Biology and Translational Medicine on Differentiated Thyroid Carcinoma, Changchun 130000, People's Republic of China

2 Department of Surgery, University of Parma, Parma, Italy

3 Department of Surgery, ASST Valle Olona, Gallarate, Italy

4 Department of Surgery, Fondazione IRCCS Ca' Granda Ospedale Maggiore Policlinico di Milano, University of Milan, Milan, Italy

5 Department of Surgery, KUMC Thyroid Center, Korea University Hospital, Korea University College of Medicine, Seoul, Republic of Korea

6 Shahid Sadoughi Yazd Medical University, Yazd, Islamic Republic of Iran

7 Endocrine Unit, Department of Medicine and Surgery, University of Insubria, ASST dei Sette Laghi, Ospedale di Circolo, Viale Borri, 57, Varèse, Italy

8 Division of Endocrine and Minimally Invasive Surgery, Department of Human Pathology in Adulthood and Childhood "G. Barresi", University Hospital "G. Martino”, University of Messina, Messina, Italy 